\title{
Laparoscopic Urological Surgery: Our Initial Experiences
}

\author{
Shiba Prasad Nandy ${ }^{1}$, AKM Akramul Bari ${ }^{2}$, Anirban Ghose ${ }^{3}$, Hasmot Ali Mia ${ }^{4}$, Md. Alamgir ${ }^{5}$, Ujjal Barua ${ }^{6}$, \\ Kazi Mohammad Monwarul Karim ${ }^{7}$, Mohammed Monowar-Ul-Hoque ${ }^{8}$
}

Received: 21 - 06 - 2020

Accepted: 28 - 08 - 2020

Conflicts of interest: None

Keywords: Laparoscopy, initial experiences, prospective.

\begin{abstract}
Introduction and Objective: Laparoscopic surgery is increasingly exercised in urology due to improvements in technical capabilities and experience. It comes with many advantages compared to open surgery such as lesser degree of pain and haemorrhage, shorter hospital stay and better cosmetic results. This study is carried out to evaluate the outcomes and complications of urological laparoscopic surgery cases performed Chittagong Medical College Hospital, Chattogram, Bangladesh.

Methods: This was a hospital based prospective observational study of total 29 patients, who received laparoscopic surgery of different kinds between January 2017 and September 2019 for urological causes with a minimum one month follow-up. Included patients were assessed in terms of demographic characteristics, preoperative diagnosis, type of laparoscopic approach, duration of surgery and hospitalization, complications after surgery and need for conversion to open surgery.
\end{abstract}

Results: The mean age was 45.03 years where 12 patients were women and 17 were male. All patients underwent trans-peritoneal procedures where 2 patients received renal cyst excision, 4 simple nephrectomy, 5 ureterolithotomy, 9 radical nephrectomy, 1 radical cystectomy, 2 adrenalectomy, 3 pyelolithotomy and 3 pyeloplasty. Three of the 29 patients required conversion to open surgery. Except these patients, no major complication or mortality was encountered. The mean duration of surgery for the most commonly applied procedures were as follows: renal cyst excision 87.5 (70-105) min, simple nephrectomy 141.25 (120-170) min, ureterolithotomy 120 (100-140) min, radical nephrectomy 215.56 (180-260) min, pyelolithotomy 120 (100-140) min, and pyeloplasty 156.67 (130-190) min. The mean hospital stay was $4.59 \pm 1.7$ (2-8) days.

Conclusions: The success and complications rate of the laparoscopic urological surgeries performed in our hospital were consistent with those reported in the literature. In the light of technological advances and increasing experience, we believe that laparoscopic surgery is an effective technique with excellent outcome along with a safe and feasible alternative to open surgery in the field of urology.

1. Resident Surgeon, Department of Urology, Chattogram Medical College Hospital, Chattogram, Bangladesh

2. Resident, Department of Urology, Chattogram Medical College, Chattogram, Bangladesh

3. Resident, Department of Urology, Chattogram Medical College, Chattogram, Bangladesh

4. Resident, Department of Urology, Chattogram Medical College, Chattogram, Bangladesh

5. Assistant Professor, Department of Urology, Cox's Bazar Medical College, Cox's Bazar, Bangladesh

6. Assistant Professor, Department of Urology, Chattogram Medical College, Chattogram, Bangladesh

7. Associate Professor, Department of Urology, Chattogram Medical College, Chattogram, Bangladesh

8. Associate Professor \& Head, Department of Urology, Chattogram Medical College, Chattogram, Bangladesh Correspondence: Dr. Shiba Prasad Nandy, Resident Surgeon, Department of Urology, Chittagong Medical College Hospital, Email: emoncmc38@gmail.com 


\section{Introduction}

Urology has long been recognized as an avid adaptor of new technologies and innovations in surgical practice. Progress in most fields in Urology in particular has been marked by an increasing use of laparoscopic surgery. Due to exponential and rapid improvement in instruments and techniques, this minimally invasive surgery becomes increasingly popular throughout the world in the 1990s and has also begun to be used in Bangladesh since then.Laparoscopic surgery comes with many advantages compared to open one, such as less pain and hemorrhage, shorter hospital stay and bet-ter cosmetic results. ${ }^{1}$ Laparoscopy was first ap-plied for pelvic lymphadenectomy in urology ${ }^{2}$, which was followed by its successful application for laparoscopic nephrectomy in children and adults ${ }^{3}$. In the following years, it has been started to be used for various indications such as UPJ obstruction, ureteral stone, nonpalpable testes, adrenal sur-gery and different oncourological procedure. In this study, we prospectively evaluated our case series of 29 patients in terms of outcomes and complications of laparoscopic surgery.

\section{Materials and methods}

The medical records of 29 patients who received laparoscopic surgery in Urology Department of Chittagong Medical College Hospital, Chattogram between January 2017 and September 2019 were prospectively evaluated. The laparoscopic procedures were performed in a single center by different surgeons using trans-abdominalmethod with no manual manipulation. Informed consent was taken from patient who was enrolled for the purpose of the study. Clearance of institutional review board (ethical review committee, CMC) was taken through proper channel. Patients were evaluated with regard to age, gender, preop-erative diagnosis, laparoscopic approach, duration of surgery and hospital stay, analgesic requirement, complications during or after surgery, pre-operative and post-operative laboratory results, blood transfu-sion and converting to open surgery. In our hospital, as part of a routine clinical procedure, patients with urinary infection were treated by oral or paren-teral antibiotics depending on urine culture re-sults. Prior to the operation, surgical informed con-sent was obtained from each patient. While magnesium citrate was started from one night before surgery and prophylac-tic antibiotics (ceftriaxone1gm) were also given 1 hour before the procedure. All patients were underwent gen-eral anesthesia. Transperitoneal laparoscopic meth-od was performed by making the patients assume a $70^{\circ}$ lateral decubitus position in most of the cases of kidney and ureter.
Patients were placed in the low lithotomy position with a Trendelenburg trend for radical cystectomy cases.

The duration of surgery was described as the time interval between placement of the first trocar and closure of the skin. A febrile status was de-scribed as a temperature above $38^{\circ} \mathrm{C}$. Postopera-tively, at day 1 , all patients were evaluated via blood count and biochemical profile after which they were discharged. Follow-up assessment was scheduled for 1 week later. All patients were scheduled to visit for further followup 1 month later. The values were expressed as mean \pm stan-dard deviation.

Although surgical technique varies slightly with different surgeons and between the sexes, several common principles were applied. Trans-peritoneal access was achieved using a Verres needle. Pneumoperito-neum was induced to achieve a $\mathrm{CO} 2$ pressure of $15 \mathrm{mmHg}$. For most of the renal and adrenal cases, the first trocar placement was performed at umbilical level, lateral to the rectus in trans-perito-neal approach. 3 standard ports (two $10 \mathrm{~mm}$ and one $5 \mathrm{~mm}$ ) were used. Depending on the difficulty encountered during liver retraction and dissection, the port number may be increased. Af-ter insertion of the trocars, intraabdominal pres-sure was reduced to $12 \mathrm{mmHg}$. During dissec-tion, both ultrasonic (Harmonic ScalpelEthicon ${ }^{\circledR}$ ) and thermal energy sources were employed. The trans-peritoneal approaches in-cluded routine severance of triangular hepatic ligament and the white line of Toldt on the right. The posterior hepatic ligament and the adrenal extension of the ascending colon were medialized. Ureter was found and suspended. On the left, unlike procedures on the right, splenecolic ligament was also severed and the colon was completely medialized.

After this stage at simple and radical nephrec-tomy, in both approaches, nonabsorbable and lock-ing polymeric clips of large and X-large size (Hem- OLok ${ }^{\mathrm{TM}}$, Research Triangle Park, NC) were placed first on the artery and then on the vein. The insignif-icant $(<7 \mathrm{~mm})$ vascular structures were treated with metal clips or ligatures. Ureter was severed by clos-ing with the metal clip. The hemorrhage was controlled under low pressure $(6 \mathrm{mmHg})$. The excised renal tissue was put into a laparoscopic bag and removed through a cutane-ous incision as small as possible. No morcellation was employed to the tissues.

Prior to the cyst excision, cases suspected of having a problem in the renal calyceal system were evaluated by retrograde pyelography. Cyst fluid was removed via aspiration and the excised cyst wall specimen was sent for pathologic interpretation. 
In ureterolithotomy and pyelolithotomy cases, the stones were removed using a grasper through a longitudinal incision made by scissors in some cases and scalpel in others, without applying any energy. Following the procedure, antegrade double J stent insertion was applied in each patient. The in-cision site was closed using a 4-0 Vicryl suture.

For dismembered pyeloplasty, antegrade insertion of the ureteral catheter was performed be-fore the operation. Subsequent to the ureteral spatu-lation, antegrade insertion of a $5 \mathrm{~F}$ double $\mathrm{J}$ stent was achieved. Anastomosis was performed using a 4-0 Vicryl.

A trans-peritoneal four/five-port technique was used for radical cystectomy. The ports were arranged in a fan-shape across the lower abdomen, with the camera port placed $2.5-5 \mathrm{~cm}$ above the umbilicus to facilitate the cranial aspect of the lymphadenectomy. The cystectomy portion of the procedure was performed initially, facilitating the subsequent LND. The posterior and lateral aspects of the bladder dissection were done first, leaving the anterior dissection, prostatic apex and urethra for the final steps.

While insertion sites of $10 \mathrm{~mm}$ trocars were closed with double suture layers in-cluding the fascia and skin, the insertion sites of the $5 \mathrm{~mm}$ trocars were closed using only single-layer sutures through the skin. All patients were treated by peri-operative ureteral catheterization and a drain was kept in situ.

\section{Results}

Among 29 patients, 12 were female and 17 were male where mean age was $40.03 \pm 12.46$ years (range: $20-65$ years). The demographic data of the study popu-lation are shown in Table 1 . All the patients $(100 \%)$ underwent trans-peritoneal approach.2 (6.9\%) patient had simple renal cyst excision, 4 (13.79\%) simple nephrectomy, 5 (17.24\%) ureterolithotomy, 9 (31.03\%) radical nephrec- tomy, 3 (10.35\%) pyelolithotomy,3 (10.35\%) pyeloplasty, $2(6.9 \%)$ adrenalectomy and $1(3.45 \%)$ radical cystectomy. Mean age of the patients was found 40.03 years and mean duration of hospital stay was 4.72 days. The total 29 operative cases are mention below (Table 2).

In this approach, the mean duration of tro-car insertion was $19.93 \pm 5.19$ (10-30) minutes. As 7 patients required the insertion of a $4^{\text {th }}$ or accessory trocar/s, no such need was observed in others. Mean operative time was $165.17 \pm 52.4$ minutes. Average amount of blood loss was found $146.88 \pm 93.93 \mathrm{ml}$. Three patients $(10.34 \%)$ required converting to open surgery. The un-derlying cause of conversion (renal mass, nonfunctioning kidney and pyeloplasty) was renal vein in-jury during placement of vascular clip and failure to dissect the pelvis/pedicledue to dense adhesions. The converting cases received one unit of perioperative blood transfusion for unwanted haemorrhage. In all these pa-tients, vital signs were stable during postoperative period. No other major complication or mortality associated with anesthesia or surgery observed. Post operatively opioid analgesic followed by injection paracetamol/ suppository were used for all the patients. Perioperative and postoperative results are shown in Table 3.

Table-I : Demographic characteristics of the patients $(n=29)$

\begin{tabular}{ll}
\hline $\begin{array}{l}\text { Gender, female/male (\%) } \\
\text { Mean age, year* }\end{array}$ & $12 / 17$ \\
$\begin{array}{l}\text { Mean duration of hospital } \\
\text { stay }(\text { day) }\end{array}$ & $40.03 \pm 12.46(20-65)$ \\
$\begin{array}{l}\text { Preoperative hemoglobin } \\
(\mathrm{mg} / \mathrm{dl})^{*}\end{array}$ & $12.13 \pm 1.15$ \\
$\begin{array}{l}\text { Postoperative hemoglobin } \\
(\mathrm{mg} / \mathrm{dl})^{*}\end{array}$ & $11.96 \pm 0.73$ \\
\hline
\end{tabular}

* mean \pm standard deviation

Table - II : Type and num-ber of laparoscopic ap-proaches

\begin{tabular}{lll}
\hline Procedure & Diagnosis & Total \\
\hline Simple nephrectomy & Nonfunctional kidney (Right 1, Left 3) & 4 \\
Radical nephrectomy & Renal tumor (Right 3, Left 6) & 9 \\
Cyst excision & Simple cyst (Right 2, Left 0) & 2 \\
Ureterolithotomy & Ureteral stone (Right 2, Left 3) & 5 \\
Pyelolithotomy & Pelvic stone (Right 2, Left 1) & 3 \\
Pyeloplasty & Ureteropelvic junction (UPJ) obstruction(Right 1, Left 2) & 3 \\
Adrenalectomy & Adrenal tumor (Right 0, Left 2) & 2 \\
Radical Cystectomy & TCC urinary bladder & 1 \\
\hline
\end{tabular}


Table-III : Comparison of operative data relative to types of laparoscopic surgery

\begin{tabular}{|c|c|c|c|c|c|c|}
\hline & $\begin{array}{c}\text { Duration of } \\
\text { surgery (min) }\end{array}$ & $\begin{array}{c}\text { Amount of } \\
\text { blood loss (ml) }\end{array}$ & $\begin{array}{c}\text { Transfusion } \\
\text { (unit) }\end{array}$ & $\begin{array}{l}\text { Duration of } \\
\text { drain (day) }\end{array}$ & $\begin{array}{l}\text { Hospital stay } \\
\text { (day) }\end{array}$ & Complications \\
\hline Simple nephrectomy & $141.25(120-170)$ & $125(50-300)$ & 1.25 & $3(2-4)$ & $3.75(3-5)$ & $1^{\mathrm{a}}$ \\
\hline Radical nephrectomy & $215.56(180-260)$ & $161.11(100-400)$ & 1.67 & $3.22(2-5)$ & $5.44(4-9)$ & $1^{b}$ \\
\hline Cyst excision & $87.5(70-105)$ & * & 0 & $1(1)$ & $2.5(2-3)$ & \\
\hline Ureterolithotomy & $120(100-140)$ & * & 0 & $2.4(2.4)$ & $3.8(3-5)$ & \\
\hline Pyelolithotomy & $120(100-140)$ & * & 0 & $2.67(2-3)$ & $4(4-5)$ & \\
\hline Pyeloplasty & 156.67 (130-190) & * & 0 & $2.67(2-3)$ & $3.8(3-5)$ & $1^{\mathrm{c}}$ \\
\hline Adrenalectomy & $225(220-230)$ & $125(100-150)$ & 1.5 & $3.5(3-4)$ & $7(6-7)$ & \\
\hline Radical Cystectomy & 230 & 150 & 2 & 4 & 8 & \\
\hline
\end{tabular}

* Insignificant hemorrhage

1a. Converted to open surgery because of failure to identify the pedicle due to adhesions in a nonfunctional kidney with a history of surgery.

1b. Converted to open surgery because of hemorrhage associated with a hem-o-lock injury during hilar vascular control.

1c. Converted to open surgery due todense adhesion.
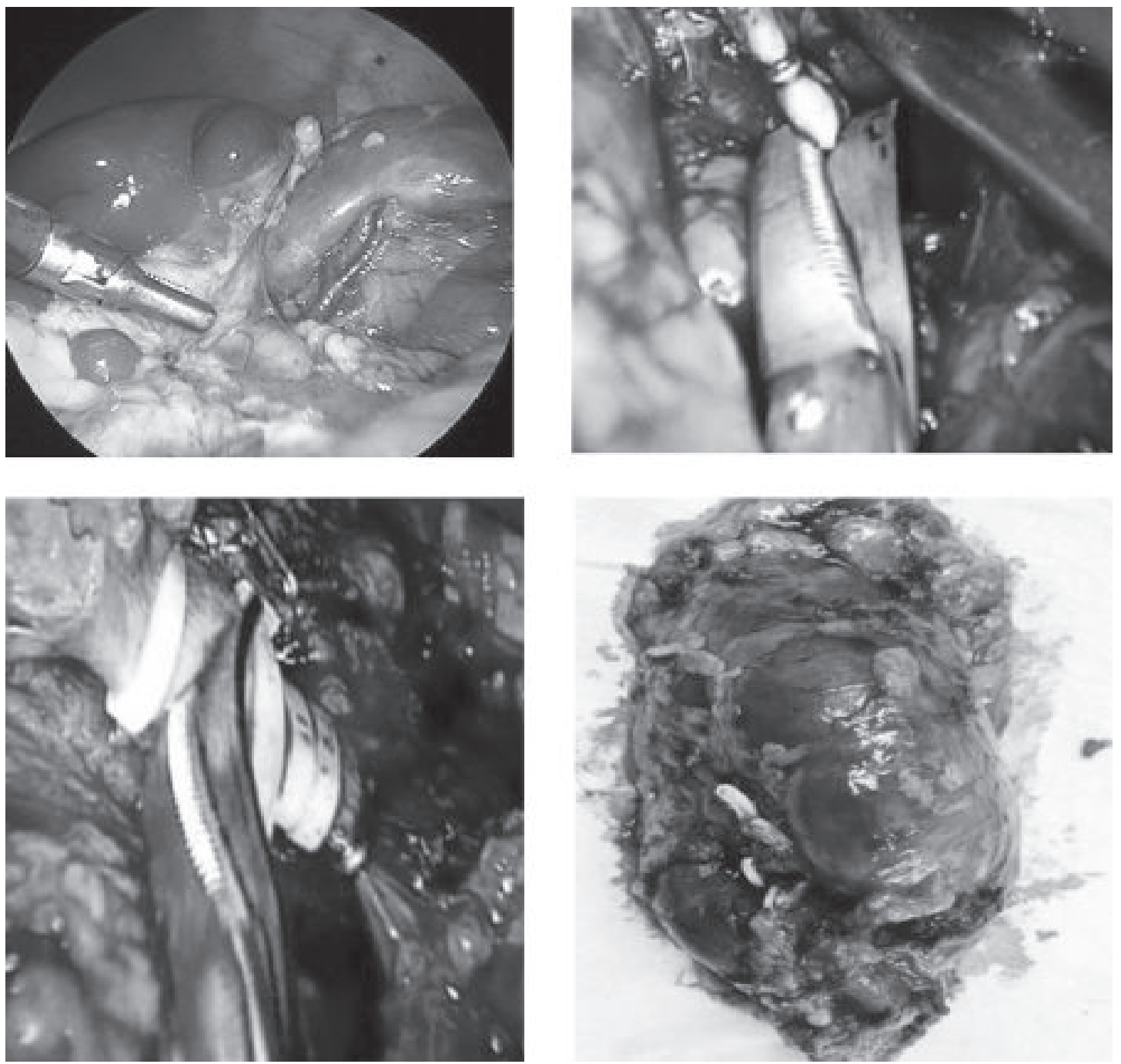

Fig.-1: Left Radical nephrectomy for RCC; a) Left kidney with tumor, b) dissection of left renal artery, c) dissection of left renal vein and d) the specimen. 
All the patients were mobilized after 24 hours. Drain was removed after a mean period of $2.83 \pm 0.93(2-5)$ days. The mean hospital stay was $4.59 \pm 1.7$ (2-8) days. The drainage was continued for 5 days in a radical nephrectomy and a radical cystectomy case. They showed excessive drainage fluid postoperatively which exhibited regression in their follow up, requiring no additional intervention. Mean hospital stay was estimated $2.81 \pm .89$ days.

\section{Discussion}

Recently, with the advent of the technological advances, laparoscopic surgery has been replacing open surgery in urology. ${ }^{1}$ Regarding approach, as trans-peritoneal is the preferred one, we used only this approach in our cases. ${ }^{4,5}$ The most important factor for choosing is, the experience and preference of the surgeon;How-ever, retroperitonealapproach also presents some advantages such as faster kidney reach, absence of any risk for intra-peritonealorgan injury, postoperative shorter hospital stay and in patients with history of abdominal surgery. 6,7

Laparoscopic surgery is most commonly applied in simple and radical nephrectomy proce-dures with more safety and lower complica-tion rates as compared to open procedure. ${ }^{8}$ The most common complications of laparoscopic nephrectomy are hemorrhage, spleen, liver and intestinal injury, unsuccessful in or-gan removal, abdominal wall hematoma, and in-traperitoneal abscess. ${ }^{9,10}$ Rasweiler et al. con-ducted a study reporting their first 100 laparoscopic experiences and noted converting to open surgery in 17 cases which was explained by them with the difficulty of the procedure and the individual learn-ing curve. ${ }^{11}$ However, in this study, only 3 cases required conversion due to hem-orrhage, technical errors and adhesions. Con-verting to open surgery is necessary in the presence of large vessel injury, impaired hemodynamics, or-gan injury, and in cases where laparoscopic experi-ence is not enough. ${ }^{11}$ In our simple nephrectomy series of 4 cases, mean surgery time was 141.25 (120-170), mean blood loss was 125 (50-30) ml, while in radical nephrectomy series of 9 cases same values were 215.56 (180-260) $\mathrm{min}$ and 161.11 (100-400) $\mathrm{ml}$, re-spectively. Kural et al. showed, mean duration of simple nephrectomy is 200 (120-300) $\mathrm{min}$ and the mean amount of blood loss is $210(50-1500) \mathrm{ml}^{12}$ which were consistent with our results.

In this series, our first laparoscopic experience was with simple renal cyst excision. The mean duration of surgery for simple renal cyst decortication was 45 minutes in different study ${ }^{13,14}$ which was 87.5 minutes in our series. We believe that, the longer duration may be associ-ated with the natural consequence of our learning curve.

Laparoscopy has been first practiced for stone surgery in urology by Wickkam in 1979. ${ }^{15}$ Lapa-roscopic ureterolithotomy has been reported to be safe and beneficial in cases of large ureteral stones impacted in the mucosa or in patients with solitary kidney where ESWL (Extracorporeal Shock Wave Lithotripsy) and endourological technology fail to succeed or may be risky. ${ }^{16}$ Of 134 laparoscopic ureterolithotomy performed by Simforoosh, 114 were transperitoneal and 20 were retroperitoneal. ${ }^{17}$ The mean duration of surgery was $143 \mathrm{~min}$., stone-free rate was $100 \%$, and side effect rate was $10 \%$. In our series, all the laparoscopic ureteral stone cases were done transperitoneally, mean duration of surgery was $120 \mathrm{~min}$ and the stone-free rate was $100 \%$. Postoperatively, none of our patients demon-strated prolonged urinary leakage and the drain was removed on an average of 2.4 days. Trans-peritoneal approach has a downside that infected urine may contact with the peritoneal space or organs. However, Janetschek et al. reported no side effects in their series of trans-ab-dominal surgeries. ${ }^{18}$ Laparoscopic kidney stonetreatment is indicated in cases where methods such as ESWL, PCNL (percutaneous nephrolithotomy), and flexible ureterorenoscopy (F-URS) fail; or in the presence of large or complex stones in ectopic or rotated kidneys or when the patient does not prefer open surgery. ${ }^{19}$ In the present study, the kidney stones were single and all were larger than $2 \mathrm{~cm}$ with no risk of push back to the calyceal system. One pa-tient had rotation anomaly and had received ESWL therapy with no success. Anotherundergone suc-cessful treatment in other hospital but stone recurrence occurred. Thus, we performed laparoscopic pyelolithotomy in 3 patients. In a study compar-ing the open and laparoscopic pyelolithotomy, the mean duration of surgery was $94.43 \mathrm{~min}$, the mean hospital stay was 3.8 days, and the mean duration of drainage was 2.7 days in the laparoscopic group. ${ }^{20}$ In the present study, the mean duration of sur-gery was 120 minutes, while the mean duration of drainage and hospital stay were 2.67 and 5 days, re-spectively. Thus, we performed laparoscopic pyelolithotomy in 3 patientsand none suffered fromany post-operative complication. Considering that we do not have F-URS devices in our hospital, we can say 
that laparoscopic procedures are not an alterna-tive to the modern techniques routinely performed in kidney stones. We believe that laparoscopic ap-proach should be carried out only in the absence of other more appropriate endoscopic methods among candidates of open surgery.

Laparoscopic pyeloplasty has been first performed at the beginning of 1990s and today it becomes the most preferred minimally invasive method in obstruction of ureteropelvic junction. ${ }^{21}$ According to the reports of various institutions performing laparoscopic pyeloplasty, it provides similar outcome as open surgery with a better quality of life. ${ }^{22,23}$ Laparoscopic pyeloplasty may be carried out using retroperitoneal or trans-peritoneal approach depend-ing on the experience and preference of the surgeon. Other factors involved in the decision are history of surgery, morbid obesity, and presence of crossing vessels. Generally, we prefer the trans-peri-toneal approach because of our higher experience with that. Converting to open surgery during lapa-roscopic pyeloplasty is generally associated with failure to dissect the ureteropelvic region, ureteral stent migration or failure to approximate ureter and pelvis. ${ }^{24,25}$, however, in our series, conversion done due to dense adhesion and inability to identify UPJ in one case.

Adrenalectomy has undergone a significant transformation since the first report of a laparoscopic adrenalectomy,published in1992. From that time, a dramatic shifting occurred from open to laparoscopic approach for both malignant and benign adrenal pathologies. Numerous studies have shown a well visualized anatomy, decreased blood loss, shorter hospital stay, shorter convalescence and low morbidity inlaparoscopic approach when compared to open surgery. The use of laparoscopy in adrenalsurgery is currently the standard of care. ${ }^{26}$ In our series, the mean operating time was 225 minutes; mean hospital stay was 7 days. No conversiontoopen surgery withno postoperative complications were reported in those 2 patients.

Laparoscopic radical cystectomy is an acceptable minimally invasive alternative to open surgery in selected patientswith the main advantage of well visualized anatomy, decreased blood loss and postoperative pain with shorter hospital stay and recovery. We had a single case of such patient, operative time was 230 minutes, 2 unit blood transfusions was made, hospital stay was 8 days and patient did not suffer from any significant postoperative complication.Anakievski et al. reported that, mean operative time 300 minutes, conversion rate 0 and mean hospital stay 7 days. ${ }^{27}$

\section{Conclusion:}

The search of patients and sur-geons for better functional outcomes and lower mor-bidity along with scar-free surgeries will continue. In this regard, laparoscopy is recognized as a safe and practicable technique acting as an alternative to open surgery in the recent years due to technologi-cal advances. Our initial experiences with laparoscopic surgery in urology are promising and consistent with the literature. We believe that our improving experience in laparoscopic surgery will make more of our patients to prefer this technique which also associate with high patient satisfaction.

Declaration of Conflicting Interests: No conflict of interestdeclared.

Financial Disclosure: No financial support was received.

\section{References}

1. Demir Ö, Öztürk B, Eðriboyun S, Esen AA. Initial experiencewith urologic laparoscopic surgery in our clinic andthe learning process. Dokuz EylülÜniversitesi Týp Fakültesi Derg 2010;24:105112.

2. Schuessler WW, Vancaillie TG, Reich H, Griffith DP. Transperitonealendosurgical lymphadenectomy in patients withlocalized prostate cancer. J Urol 1991;145:988-991.

3. Clayman RV, Kavoussi LR, Soper NJ, et al. Laparoscopicnephrectomy: initial case report. J Urol 1991;146:278-282.

4. Chung JH, Lee SW, Lee KSet al. Safety of en bloc ligationof the renal hilum during laparoscopic radical nephrectomyfor renal cell carcinoma: a randomized controlled trial. J Laparoendosc AdvSurg Tech A 2013;23:489-494.

5. Rassweiler J. Laparoscopic radical prostatectomy is also oncologicallysafe and effective! BJU Int 2013;112:158.

6. Leclair MD, Vidal I, Suply E, et al. Retroperitoneal laparoscopicheminephrectomy in duplex kidney in infants andchildren: a 15 -year experience. EurUrol 2009;56:385-389. 
7. Kim C, McKay K, Docimo S. Laparoscopic nephrectomy inchildren: systemic review of transperitoneal laparoscopicand retroperitoneal approaches. Urology 2009;73:280-284.

8. Daðgulli M, Utanðaç MM, Bozkurt Y, et al. Our laparoscopicradical nephrectomy experiences. Dicle Med J2014;41:732-737.

9. Keeley FX, Tolley DA. A review of our first 100 cases oflaparoscopic nephrectomy: Defining risk factors for complications.Br J Urol 1998;82:615618.

10. Siqueira TM, Kuo RL, Gardner TA, et al. Major complicationsin 213 laparoscopic nephrectomy cases: The Indianopolisexperience. J Urol 2002;168:1361-1365.

11. Rassweiler JJ, Seemann O, Henkel T, et al. Retroperitoneoscopy.Technique and experiences with the first 100 patients.Urol A 1996; 35: 185195.

12. Kural AR, Demirkesen O, Akpýnar H, et al. Our initialexperiences with laparoscopic nephrectomy. Turk J Urol2004;30:414-421.

13. Hatipoðlu NK, Penbegül N, Söylemez H, et al. Urologicallaparoscopic surgery: Our experience of first 100 cases inDicle University. J ClinExp Invest 2012;3:44-48.

14. Bayraktar AM, Ölçücüoðlu E, Taptemur S, et al. Initial resultsof our laparoscopic urological surgery: Firs 32. FýratMedical Journal 2014;19:7578.

15. Wickham JEA. The surgical treatment of renal lithiasis. In:Urinary Calculous Disease. edn. Edited by JEA W: NewYork, NY: ChurchillLivingstone; 1979: 145-198.

16. Gaur DD, Trivedi S, Prabhudesai MR, et al. Laparoscopicureterolithotomy: technical considerations and long-termfollow-up. BJU Int 2002;89:339-343.
17. Simforoosh N, Bassiri A, Danesh A, et al. Laparoscopicmanagement of upper urinary tract stones: a report of 134cases. Urology 2006;68:15.

18. Nambirajan T, Jeschke $S$, Albqami N, et al. Role of laparoscopyin management of renal stones: single-center experienceand review of literature. J Endourol 2005;19:353-359.

19. Türk C, Knoll T, Petric A, et al. Guidelines on urolithiasis.European Association of Urology, Guidelines 2015.

20. Patloo AM, Sarmast AH, Khan MA, et al. Laparoscopicretroperitoneal pyelolithotomy and open pyelolithotomy: acomparative study. Turk J Urol 2012;38:195-200.

21. Schuessler WW, Grune MT, Tecuanhuey LV, PremingerGM. Laparoscopic dismembered pyeloplasty. J Urol1993;150:1795-1799.

22. Eden CG. Minimally invasive treatment of ureteropelvicjunction obstruction: a critical analysis of results. Eur Urol.2007;52:983-989.

23. Tan BJ, Rastinehad AR, Marcovich R, et al. Trends in urtereropelvicjunction obstruction management among urologistsin the United States. Urology 2005;65:260-264.

24. Soulie M, Seguin P. Urological complications of laparoscopicsurgery: Experience with 350 procedures at a singlecenter. J Urol 2002; 165: 1960-1963.

25. Rassweiler JJ, Teber D, Frede T. Complications of laparoscopicpyeloplasty. World J Urol 2008; 26:539-547.

26. Khan A, Abbas A, Fatima T, Nawaz A, Khan WH, Butt UI \&Ayyaz M. Our Initial Experience: Laparoscopic Adrenalectomy. PJMHS2013;7:288290.

27. Anakievski D, Hinev A, Marinov R, Gocheva I \&Nikolov V. Laparoscopic Radical Cystectomy Initial Experience. Scripta Scientific a Medica 2017;49:31-37. 